Научная рецензия / Book review

Новые страницы биографии С.Л. Франка

в контексте диалога российской

и западной философских культур

\author{
А.Ю. Бердникова
}

Институт философии РАН

ул. Гончарная, д. 12, стр. 1, Москва, Российская Федерация, 109240

\title{
New Pages of S.L. Frank's Biography in the Context of the Dialogue between Russian and Western Philosophical Cultures
}

\author{
A.Y. Berdnikova \\ RAS Institute of Philosophy \\ 12 - 1 Goncharnaya Str., Moscow, Russian Federation, 109240
}

Информация о финансировании и благодарности. Рецензия подготовлена в рамках гранта РФФИ № 19-011-00764 «Современная зарубежная рецепция русской философии».

\section{История статьи:}

Статья поступила: 21.02.2020

Статья принята к публикации:10.03.2020

Для цитирования: Бердникова А.Ю. Новые страницы биографии С.Л. Франка в контексте диалога российской и западной философских культур // Вестник Российского университета дружбы народов. Серия: Философия. 2020. Т. 24. о 3. C. 518-526. DOI: 10.22363/2313-2302-2020-24-3-518-526

Funding and Acknowledgement of Sources. The book review was funded by RFBR, project number 19-011-00764a (project participant, 2019-2021) "Current reception of Russian philosophy abroad".

(C) Бердникова А.Ю., 2020

(c) This work is licensed under a Creative Commons Attribution 4.0 International License https://creativecommons.org/licenses/by/4.0/ 


\section{Article history:}

The article was submitted on 21.02.2020

The article was accepted on 10.03.2020

For citation: Berdnikova A.Y. New pages of S. L. Frank's biography in the context of the dialogue between Russian and Western philosophical cultures. RUDN Journal of Philosophy. 2020; 24 (3): 518 - 526. DOI: 10.22363/2313-2302-2020-24-3-518-526

Одно из лидирующих мест в современных исследованиях из области истории русской философии по праву принадлежит фигуре С.Л. Франка. Примеров пристального внимания к возрождению интеллектуального наследия этого мыслителя множество. Среди них монографии как отечественных, так и зарубежных ученых, посвященные изучению идей этого философа ${ }^{1}$; отдельные статьи, охватывающие не только начальный, российский этап эволюции его творчества, но также и пока малоисследованные источники, связанные с развитием его идей в период эмиграции ${ }^{2}$. Важным показателем пристального исследовательского интереса к трудам Франка как в России, так и на Западе можно также считать проекты собрания его сочинений: первый, успешно осуществленный в 2000-2013 гг. в Германии усилиями как зарубежных (инициатором и главным редактором издания этого собрания сочинений стал профессор Католического университета Айхштетт-Ингольштадт Л. Люкс; в подготовке томов также активное участие приняли П. Шульц, П. Элен, Н. Лобкович, Д. Штаммер и др.), так и российских (Н.В. Мотрошилова,

\footnotetext{
${ }^{1}$ Из монографий о С.Л. Франке, вышедших за последние годы, можно отметить работы Т. Оболевич, О.А. Назаровой, П. Элена, В.К. Кантора, А.А. Гапоненкова и др. В данной рецензии проводится анализ двух недавно вышедших монографий А.С. Цыганкова и Т. Оболевич. См.: Цыганков А.С., Оболевич Т. Немецкий период философской биографии С.Л. Франка (новые материалы). М.: ИФ РАН, 2019. 272 с.; Цыганков А.С., Оболевич Т. Голландский эпизод в философской биографии С.Л. Франка (новые материалы). М.: ИФ PAH, 2020. $336 \mathrm{c}$.

2 К таковым относятся, в первую очередь, работы О.А. Назаровой, Т. Оболевич, Г.Е. Аляева, Т.Н. Резвых, К.М. Антонова, А.А. Гапоненкова, А.С. Цыганкова и др. Одним из перспективных проектов, относящихся к области исследования диалога русской и западной философии, можно также назвать активно ведущееся в данный момент изучение и подготовку к изданию обширной и многолетней переписки С.Л. Франка со швейцарским психиатром и одним из основоположников экзистенциальной психологии Л. Бинсвангером (1881-1966). Подробнее об этом см.: Гапоненков А.А., Цыганков А.С. «Симфоническое философствование» (биографические реалии переписки С.Л. Франка и Л. Бинсвангера) // Вестник ПСТГУ. Серия І. Богословие. Философия. Религиоведение. 2019. Вып. 85. С. 88-107; Цыганков А.С., Оболевич Т. История семьи и творчества С.Л. Франка в переписке Л. Бинсвангера и Т.С. Франк // Философия. Журнал высшей школы экономики. 2018. № 2. С. 134-155 и т.д. Показателем пристального внимания к исследованию наследия С.Л. Франка можно считать в том числе и новые энциклопедические статьи о нем, вышедшие за последнее время. См., к примеру: Аляев Г.Е., Цыганков А.С. Семен Людвигович Франк // Электронная философская энциклопедия. 2019. T. 3. Институт философии PAH. URL: ttps://www.elenph.org/library/collection/elphilenc/document/HASHe6908ebf6a9b5cf27fe1
} 
А.А. Гусейнов, В.К. Кантор и др.) ученых ${ }^{3}$; и второй, русскоязычный проект издания собрания сочинений мыслителя, реализация которого осуществляется на данный момент на базе Православного Свято-Тихоновского гуманитарного университета. На сегодняшний день из печати вышли первые два тома этого собрания сочинений, и, судя по ним, можно с надеждой утверждать, что во многом этот проект уже обещает быть более фундаментальным и масштабным, нежели немецкий, за счет привлечения ранее не публиковавшихся материалов мыслителя (к которым можно отнести проекты ранних статей, черновики более поздних произведений, переписку, архивные материалы и т.д. $)^{4}$.

Показательный пример совместного российско-западного исследования творчества Франка являют собой и обе рецензируемые книги, вышедшие одна за другой в 2019 и 2020 гг. соответственно. Оба этих труда можно с полным правом назвать закономерным итогом многолетних совместных «франковедческих» исследований А.С. Цыганкова и Т. Оболевич 5 .

В плане содержания и структурного построения текста эта «преемственность» в лучшем смысле слова просматривается, если мы обратимся, к примеру, к более ранней книге Т. Оболевич «Семен Франк. Штрихи к портрету философа» $[1]^{6}$. И там, и здесь книги по своей структуре разделены на две основных части: непосредственно исследовательскую часть и впервые публикуемые ранее неизвестные тексты философа (по большей части относящиеся к его архивному либо эпистолярному наследию). Более того, если пристально сравнить все эти книги, то можно прийти к заключению о том, что их вполне можно рассматривать в качестве продолжающих и взаимодополняющих друг друга частей единой серии. Подтверждение этого можно

\footnotetext{
${ }^{3}$ Cм.: Frank Simon L. Werke in acht Bänden (Bearbeitet von Peter Schulz, Peter Ehlen, Nikolaus Lobkowicz und Leonid Luks). Freiburg; München, 2008-2013. Подробнее об этом см.: Антонов К.М., Болдарева В.Н. С.Л. Франк между Россией и Европой (по материалам научной конференции) // Вопросы философии. 2014. № 10. С. 170-176; Мотрошилова Н.В. О немецком издании сочинений С.Л. Франка // «Самый выдающийся русский философ»: Философия религии и политики С.Л. Франка: Сборник научный статей / Сост. К.М. Антонов. М.: Изд-во ПСТГУ, 2015. С. 38-49.

${ }^{4}$ См.: Франк С.Л. Полное собрание сочинений. Т. 1: 1896-1902 / Под общ. ред. Г.Е. Аляева, К.М. Антонова, Т.Н. Резвых. М.: Изд-во ПСТГУ, 2018. 720 с.; Франк С.Л. Полное собрание сочинений. Т. 2: 1903-1907 / Под общ. ред. Г.Е. Аляева, К.М. Антонова, Т.Н. Резвых. М.: Изд-во ПСТГУ, 2019. 768 с.

Более подробно о русскоязычном проекте собрания сочинений С.Л. Франка см.: Ермичёв А.А. К выходу в свет первого и второго томов полного собрания сочинений С.Л. Франка // Вестник Русской христианской гуманитарной академии. 2019. Т. 20. Вып. 3. C. $398-402$.

${ }^{5}$ Александр Сергеевич Цыганков - старший научный сотрудник Института философии РАН; Тереза Оболевич — ординарный профессор философского факультета Папского университета им. Иоанна Павла II, г. Краков (Польша).

${ }^{6}$ Отдельного внимания также заслуживает недавно вышедший труд исследовательницы на эту тему. См.: Оболевич Т. Семен Франк, Лев Карсавин и евразийцы. М.: Модест Колеров, $2020.304 \mathrm{c}$.
} 
найти и в словах самих авторов из предисловия к пока наиболее свежей из всех перечисленных книге «Голландский эпизод в философской биографии С.Л. Франка (новые материалы)»: «Книга, которую читатель держит в руках, продолжает проект изучения малоизвестных страниц жизни и творчества Франка периода эмиграции» [2;3].

Если же перейти непосредственно к обзору рецензируемых здесь книг, то можно отметить, что обе они представляют собой результат долгой и кропотливой работы, связанной с детальной реконструкцией эмигрантского периода жизни и творчества С.Л. Франка (и косвенно - с реконструкцией культуры русской пореволюционной эмиграции в целом). К сожалению, можно также отметить, что подобная тематика в рамках историко-философских исследований русской мысли на данный момент представлена слабо. Во многом это связано с труднодоступностью для российских исследователей зарубежных архивных материалов, которые в большинстве случаев являются исчерпывающим источником информации, позволяющим восстановить те или иные нюансы личной и творческой биографии русских мыслителей в эмиграции. Этим можно объяснить отсутствие полноценного исследования эмигрантского периода жизни и деятельности Н.А. Бердяева, Н.О. Лосского, Л. Шестова и многих других русских мыслителей. В этой связи радует факт появления подобного исследования творческого пути С.Л. Франка, связанного, в частности, с его немецкой эмиграцией в 1922-1937 гг,, а также с поездками в Голландию в 1930-1934 гг. и плодотворным сотрудничеством с голландскими мыслителями и издателями, чему посвящены непосредственно сами рецензируемые книги ${ }^{7}$.

Первая из представленных здесь книг, «Немецкий период философской биографии С.Л. Франка (новые материалы)», призвана раскрыть и прояснить «избранные страницы немецкого периода жизни и творчества Семена Людвиговича Франка» [4; 5]. В число этих «избранных страниц» входит биографическое «родство» предков и членов мыслителя с немецкой культурой, обзор чего представлен читателю в Предисловии [4-6] его личный интерес к немецкой философии и идеям отдельных ее представителей (Г. Зиммеля, Ф. Ницше, Ф. Шлейермахера, В. Виндельбанда, М. Шелера, Ф. Баадера, И.В. фон Гёте, Ф. Розенцвейга, Г. Когена, Э. Кассирера, М. Бубера и др.); доэмигрантские поездки в Германию и стажировка в немецких университетах (в Берлин (1899-1901), Штутгарт и Мюнхен (1903-1904), Марбург и Хершинге-ам-Аммерз (1913-1914)); и, наконец, собственно пребывание

\footnotetext{
${ }^{7}$ Стоит также отметить исследования О.А. Назаровой, связанные с реконструкцией эмигрантского периода жизни и творчества С.Л. Франка: Назарова О.А. Швейцарские публикации Семена Людвиговича Франка // Вопросы философии. 2007. № 1. С. 145-157; Назарова O.A. Неизвестные публикации Семена Людвиговича Франка в журнале «Liebet einander» // Философские науки. 2007. № 2. С. 5-9; Назарова О.А. Немецкие публикации С.Л. Франка о старчестве // Соловьевские исследования. 2012. № 4 (36). С. 139-143; Назарова О.А. «Великий разрыв»: опыт характеристики творчества С. Л. Франка в изгнании (1922-1950) // Русское зарубежье. 2013. № 2. С. 69-115 и т.д.
} 
Франка в Германии в течение 15 лет после эмиграции из России (чему посвящена вторая часть рецензируемого исследования). В целом, такой всесторонний анализ позволяет получить практически исчерпывающее представление как о важности влияния на эволюцию взглядов Франка идей немецких философов (из которых, безусловно, «первое место» занимает фигура Николая Кузанского, - одного из немногих мыслителей, влияние которого на себя признавал сам Франк, считая его «единственным учителем философии» [5. С. 184]); так и о непосредственных моментах личной биографии мыслителя, напрямую связанных с Германией и «немецким влиянием» на становление его учения и основных идей, что впоследствии привело к формированию в среде исследователей истории русской философии мнения о Франке как о «самом немецком из русских философов» [7. С. 198]. Авторами рисуется широкая панорама «немецкого периода» творческой биографии Франка, тесно связанного с именами таких выдающихся персоналий, как: П.Ф. Андерсон, Г.Г. Кульман, А. Эйнштейн [3], Ф. Либ, П. Эренфест, М. Фасмер, Л. Бинсвангер, Д. Лаури, А. Либерт, Г. Якоби, Н.Н. Бубнов, Ф. Хайлер [6], П. Тиллих и др.; а также деятельностью таких организаций, как: Американская молодежная христианская ассоциация (YMCA), Религиозно-философская академия и Русский научный институт в Берлине, Славянский институт Берлинского университета Фридриха Вильгельма, Кантовское общество (Kant-Gesellschaft) и т.д.

Во второй части книги опубликованы ранее неизвестные тексты русского философа, напрямую связанные с «берлинским» периодом его творческой биографии. К ним относятся: блок «билингвальных» статей (написанных Франком в 1930-е гг. и представленных в книге одновременно в немецком оригинале и русском переводе), исходные экземпляры которых хранятся в Бахметевском архиве Колумбийского университета США: «О смысле страдания в русской литературе», «Мировоззрение русских писателей», «Русская религиозность», «Русский религиозный социалист» (о Н.А. Бердяеве), «Русский христианский гуманист» (о Тихоне Задонском); а также статьи, которые были изначально написаны на русском языке: «Государство и церковь в восточном православии» и «О смысле страдания». Кроме этого, представлена переписка Франка с М.М. Федоровым (1929-1931; 1933), оригинал которой находится в Архиве Дома Русского зарубежья им. А. Солженицына. В качестве отдельного Приложения представлена билингвальная публикация беседы П.Ф. Андерсона с Франком (1923; оригинал - на английском языке и русскоязычный перевод), раскрывающая детали высылки философа из России; а также Письма М. Фасмера в Прусское министерство науки, искусства и народного образования (1930-1932 гг.), оригиналы которых хранятся в архиве Берлинского университета им. Гумбольдта. В завершение данного блока опубликованы документы С.Л. Франка, связанные с Советом академической помощи и другими организациями (1934-1945 гг.; анкеты, автобиографии, curriculum vitae, списки 
научных работ, рекомендательные письма и т.д.). Следует отметить, что публикация каждого из вышеназванных текстов предваряется отдельной вступительной статьей и сопровождается подробным комментарием, что является дополнительным свидетельством высокого академического уровня рецензируемой здесь книги в целом.

Вторая из рецензируемых здесь работ, «Голландский эпизод в философской биографии С.Л. Франка (новые материалы)», во многом наследует и продолжает развивать идеи, заложенные в первой книге, посвященной анализу немецкого периода творчества Франка. Здесь интерес авторов концентрируется на реконструкции сотрудничества Франка с различными голландскими организациями, университетами и учеными, благодаря которым свет увидел также ряд публикаций русского мыслителя, написанных как на нидерландском, так и на немецком языках. Центральное место в данном исследовании занимает фигура Бруно Беккера (1885-1968), голландского филолога и историка немецкого происхождения, главного организатора лекционных поездок Франка в Голландию в 1930-1934 гг., фотография русского мыслителя с которым, помимо прочего, помещена на обложку рецензируемого труда. Первая часть книги, по уже сложившейся у авторов традиции, посвящается анализу «голландского влияния» в раннем творчестве Франка (сюда относится его знакомство с физиком-теоретиком П. Эренфестом и его семьей), а также детальному анализу его поездок, лекционных курсов и докладов, прочитанных в данной стране уже после эмиграции (в ходе которых были задействованы такие города, как: Лейден, Утрехт, Роттердам, Гаага, Амстердам, Дельфт, Амерсфорт и т.д.). Заканчивается первая часть анализом последней предпринятой Франком в 1934 г. поездки в Голландию, в ходе которой состоялось его знакомство с уже упоминавшимся выше швейцарским психиатром Л. Бинсвангером. В самом конце рецензируемой монографии информация обо всех поездках С.Л. Франка в Голландию систематизирована и представлена в виде таблицы [2. С. 314].

Вторая часть рецензируемой книги посвящена непосредственному анализу «голландского текста» Франка, а также реконструкции его «неосуществленных» творческих планов, связанных с этой страной. В Приложении, уже по устоявшейся в более ранних трудах авторов традиции, мы можем увидеть ранее неопубликованные тексты, относящиеся к «голландскому периоду» творчества философа, оригинальные версии которых были обнаружены авторами в архивах и библиотеках Англии, Бельгии, Голландии, Германии, Израиля, России, США и Чехии. К таковым относятся: две лекции, прочитанные Франком в Голландии в 1932-1934 гг., представленные в виде немецкоязычного оригинала и перевода на русский язык: «Духовный кризис нашего времени» и «Антиномия между свободой и равенством»; статьи: «Дух большевизма. Роковая дилемма европейского человечества» (1931), «Православная церковь в России» (1935), «Александр Пушкин (к столетию смерти, 11 февраля 1937 г.)» (1937), «Достоевский и кризис гуманизма» (1933), 
«Бунин» (1936) (более подробно о подготовке Франком к изданию на голландском языке текстов И.А. Бунина в 1934 г., в частности, работы «Дело корнета Елагина» [8]). Также в книге представлена переписка Франка с Б. Беккером и П. Эренфестом. При этом, к сожалению, в отличие от первой рецензируемой книги, тексты статей (в отличие от конспектов лекций и переписки) представлены здесь лишь в русском переводе, без оригинального нидерландского (либо же немецкого) текста. Но данный незначительный недочет, скорее всего, следует списать на ограниченный объем монографии.

Отдельным плюсом как первой, так и второй рецензируемых здесь книг является наличие развернутого списка литературы, включающего в себя перечень архивных, газетных и прочих источников, к которым обращались авторы во время своей работы.

В завершение представленного краткого обзора остается лишь сожалеть, что наравне со столь обстоятельными исследованиями, посвященными немецкому и голландскому «эпизодам» творческой биографии С.Л. Франка, для читателя остаются по-прежнему нераскрытыми еще ряд моментов, связанных с влиянием на становление и развитие взглядов мыслителя других западных стран: Италии (где Франк провел короткое время в 1903 г. (посетив города Локарно, Лугано и Венецию) [4], а затем был приглашен вместе с другими представителями русской эмиграции в 1923 г. (Н.А. Бердяевым, М.А. Осоргиным, Б.П. Вышеславцевым и др.) выступать с публичными лекциями в Риме [9. С. 229]), Франции (где Франк жил после отъезда из Германии в 1937 г. до 1945 г.) и Великобритании, где русский мыслитель провел последние пять лет своей жизни. И здесь следует отметить, что поздний период эмигрантской биографии русского мыслителя представляет особенный интерес для современного франковедения, поскольку именно с ним связана история создания таких знаковых его произведений, как «Непостижимое. Онтологическое введение в философию религии» (1939) «Свет во тьме: опыт христианской этики и социальной философии» (1941), «С нами Бог» (1946), «Реальность и человек. Метафизика человеческого бытия» (1949) и т.д. Единственным и главным источником информации об интеллектуальных связях Франка с этими странами по-прежнему остается биография мыслителя, написанная британским исследователем Ф. Буббайером в 1995 г. И даже самим Буббайером в предисловии к русскоязычному изданию этой книги, увидевшему свет в 2001 г., было отмечено, что вышеназванные работы, равным образом как «деятельность Франка в эмиграции» в целом, еще «требуют систематического анализа» $[10 ; 2]$. Но, будем надеяться, что такого рода исследования в скором времени появятся, и количество «лакун» в изучении русской эмигрантской культуры и философской традиции будет год от года только сокращаться. 


\section{Список литературы}

[1] Нобл И., Бауерова К., Нобл Т., Парушев П. Пути русского богословия на Запад в XX веке / Пер. с чешск. С. Гаген, Ю. Янчаркова. М.: Из-во ББИ, 2016. 337 с.

[2] Цыганков А.С., Оболевич Т. Голландский эпизод в философской биографии С.Л. Франка (новые материалы). М.: ИФ РАН, 2020. 336 с.

[3] Оболевич Т. Семен Франк. Штрихи к портрету философа. М.: ББИ, 2017. 202 с.

[4] Цыганков А.С., Оболевич Т. Немецкий период философской биографии С.Л. Франка (новые материалы). М.: ИФ РАН, 2019. 272 с.

[5] Оболевич Т., Цыганков А.С. С.Л. Франк в Голландии: контуры творческого и жизненного пути // Философский журнал. 2019. № 4. С. 143-160.

[6] Цыганков А.С., Оболевич Т. «Германия уже стала для меня моей второй родиной»: жизненный и творческий путь С.Л. Франка в переписке с Ф. Хайлером et circum // Историко-философский ежегодник 2018. С. 293-313.

[7] Аляев Г.Е. О философском методе С. Франка (феноменология не по Гуссерлю) // Идейное наследие С.Л. Франка в контексте современной европейской культуры / Ред. В. Порус. М.: Изд-во: ББИ, 2009. С. 197-211.

[8] Оболевич Т., Цыганков А.С. Свидетели «великого перелома»: переписка С.Л. Франка и А. Эйнштейна // Вопросы философии. 2018. № 11. С. 111-116.

[9] Франк С.Л. Непостижимое. Онтологическое введение в философию религии // Франк С.Л. Сочинения. М.: Правда, 1990. С. 183-559.

[10] Буббайер Ф. С.Л. Франк: Жизнь и творчество русского философа, 1877-1950 / Пер. с англ. М.: РОССПЭН, 2001. 328 с.

\section{References}

[1] Nobl I, Bauerova K, Nobl T, Parushev P. Puti russkogo bogosloviya na Zapad v XX veke [The Ways of Russian Theology to the West in 20th Century] Moscow: Iz-vo BBI, 2016. $337 \mathrm{p}$.

[2] Tsygankov AS, Obolevich T. Gollandskii epizod v filosofskoi biografii S.L. Franka (novye materialy) [Dutch episode in the philosophical biography of S.L. Frank (new materials)]. Moscow: IPh RAS, 2020. 336 p.

[3] Obolevich T. Semen Frank. Shtrikhi k portretu filosofa [Simon Frank. Strokes to the Portrait of the Philosopher]. Moscow: BBI, 2017. 202 p.

[4] Tsygankov AS, Obolevich T. Nemetskii period filosofskoi biografii S.L. Franka (novye materialy) [The German Period of Philosophical Biography of S.L. Frank (New Materials)]. Moscow: IPh RAS, 2019. 272 p.

[5] Obolevich T, Tsygankov AS. S.L. Frank v Gollandii: kontury tvorcheskogo I zhiznennogo puti [S.L. Frank in Holland: a contour of the philosopher's intellectualand life path in the 1930s] In: The Philosophy Journal. 2019; (4): 143-160.

[6] Tsygankov AS, Obolevich T. "Germaniya uzhe stala dlya menya moei vtoroi rodinoi»: zhiznennyi I tvorcheskii put' S.L. Franka v perepiske s F. Khailerom et circum ["Germany has already become my second homeland for me": the life and creativity of S.L. Frank in correspondence with F. Heiler et circum] In: Istoriko-filosofskii ezhegodnik. 2018. P. 293-313.

[7] Alyaev GE. O filosofskom metode S. Franka (fenomenologiya ne po Gusserlyu) [On the philosophical method of S. Frank (phenomenology not according to Husserl)]. In: Ideinoe nasledie S.L. Franka v kontekste sovremennoi evropeiskoi kul'tury [Ideological heritage of S.L. Frank in the context of modern European culture] Ed. by V. Porus. Moscow: Izd-vo: BBI, 2009. P. 197-211. 
[8] Obolevich T, Tsygankov AS. Svideteli «velikogo pereloma»: perepiska S.L. Franka $i$ A. Einshteina [The Witnesses of "The Great Break": S.L. Frank and A. Einstein's Correspondence] In: Voprosy filosofii. 2018; (11): 111-116.

[9] Frank SL. Nepostizhimoe. Ontologicheskoe vvedenie $v$ filosofiyu religii [The Incomprehensible. An ontological introduction to the philosophy of religion]. In: Frank S.L. Sochineniya [Works]. Moscow: Pravda, 1990. P. 183-559.

[10] Boobbyer Ph. S.L. Frank: Zhizn' i tvorchestvo russkogo filosofa, 1877-1950 [S.L. Frank: The life and work of a Russian philosopher, 1877-1950]. Moscow: ROSSPEN, 2001. 328 p.

\section{Сведения об авторе:}

Бердникова Александра Юрьевна - кандидат философских наук, научный сотрудник, Институт философии РАН, Москва, Россия (e-mail: alexser015@yandex.ru).
About the author:
Berdnikova Alexandra Y. - Ph.D. in Philosophy, Research assistant of the Department of the History of Russian Philosophy, RAS Institute of Philosophy, Moscow, Russia (e-mail: alexser015@yandex.ru). 